\title{
Clinical Outcomes of Zirconia Dental Implants: A Systematic Review
}

Pieralli, S ; Kohal, R J ; Jung, R E ; Vach, K ; Spies, B C

\begin{abstract}
To determine the survival rate and marginal bone loss (MBL) of zirconia dental implants restored with single crowns or fixed dental prostheses. An electronic search was conducted up to November 2015 (without any restriction regarding the publication time) through the databases MEDLINE (PubMed), Cochrane Library, and EMBASE to identify randomized controlled clinical trials and prospective clinical trials including $>15$ patients. Primary outcomes were survival rate and MBL. Furthermore, the influence of several covariates on MBL was evaluated. Qualitative assessment and statistical analyses were performed. This review was conducted according to preferred reporting items for systematic reviews and meta-analyses (PRISMA) guidelines for systematic reviews. With the applied search strategy, 4,196 titles could be identified. After a screening procedure, 2 randomized controlled clinical trials and 7 prospective clinical trials remained for analyses. In these trials, a total of 326 patients received 398 implants. The follow-up ranged from 12 to 60 mo. Implant loss was mostly reported within the first year, especially within the healing period. Thereafter, nearly constant survival curves could be observed. Therefore, separate meta-analyses were performed for the first and subsequent years, resulting in an implant survival rate of $95.6 \%$ (95\% confidence interval: $93.3 \%$ to $97.9 \%$ ) after 12 mo and, thereafter, an expected decrease of $0.05 \%$ per year $(0.25 \%$ after 5 y). Additionally, a meta-analysis was conducted for the mean $\mathrm{MBL}$ after $12 \mathrm{mo}$, resulting in $0.79 \mathrm{~mm}$ (95\% confidence interval: 0.73 to $0.86 \mathrm{~mm}$ ). Implant bulk material and design, restoration type, and the application of minor augmentation procedures during surgery, as well as the modes of temporization and loading, had no statistically significant influence on MBL. The short-term cumulative survival rates and the MBL of zirconia implants in the presented systematic review are promising. However, additional data are still needed to confirm the long-term predictability of these implants.
\end{abstract}

DOI: https://doi.org/10.1177/0022034516664043

Posted at the Zurich Open Repository and Archive, University of Zurich

ZORA URL: https://doi.org/10.5167/uzh-126656

Journal Article

Accepted Version

Originally published at:

Pieralli, S; Kohal, R J; Jung, R E; Vach, K; Spies, B C (2017). Clinical Outcomes of Zirconia Dental Implants: A Systematic Review. Journal of Dental Research, 96(1):38-46.

DOI: https://doi.org/10.1177/0022034516664043 


\section{Clinical outcomes of zirconia dental implants: a systematic review.}

\section{Stefano Pieralli ${ }^{1 *}$}

Ralf-Joachim Kohal $^{1^{*}}$, Prof. Dr. med. dent.

Ronald E. Jung ${ }^{2}$, Prof. Dr. med. dent.

Kirstin Vach ${ }^{3}$, Dipl.-Math.

Benedikt Christopher Spies ${ }^{1}$, Dr. med. dent.

* These authors contributed equally to this work

1 Medical Center - University of Freiburg, Center for Dental Medicine, Department of Prosthetic Dentistry, Freiburg, Germany

2 Clinic of Fixed and Removable Prosthodontics and Dental Material Science, Center of Dental Medicine, University of Zurich, Zurich, Switzerland

3 Medical Center - University of Freiburg, Center for Medical Biometry and Medical Informatics, Institute for Medical Biometry and Statistics, Freiburg, Germany

Corresponding author:

Stefano Pieralli

Department of Prosthetic Dentistry

Hugstetter Straße 55, 79106 Freiburg, Germany

Phone: +49 761 270-49800, Fax: +49 $761270-48240$

Email: stefano.pieralli@uniklinik-freiburg.de

Abstract word count: 299 words

Total word count: $\quad 4000$ words (Introduction $\rightarrow$ Conclusion)

Number of tables/figures: $6(4 / 2)$

Number of references: 58

Keywords [MeSH]: $\quad$ ceramics, zirconium dioxide, bone resorption, dental implant, meta-analysis, osseointegration

The research is original, not under publication consideration elsewhere, and free of conflict of interest. 


\section{Abstract}

Objective: To determine the survival rate and marginal bone loss (MBL) of zirconia dental implants restored with single crowns (SCs) or fixed dental prostheses (FDPs).

Materials and methods: An electronic search was conducted up to November 2015 without any restriction considering the publication time through the databases MEDLINE (PubMed), Cochrane Library and Embase to identify randomized controlled clinical trials (RCTs) and prospective clinical trials including more than 15 patients. Primary outcomes were survival rate and MBL. Furthermore, the influence of several covariates on MBL was evaluated. Qualitative assessment and statistical analyses were performed. This review was conducted according to PRISMA guidelines for systematic reviews.

Results: With the applied search strategy, 4196 titles could be identified. After a screening procedure, two RCTs and seven prospective clinical trials remained for analyses. In these trials, a total of 326 patients received 398 implants. The follow-up ranged from 12 to 60 months. Implant loss was mostly reported within the first year, especially within the healing period. Thereafter, nearly constant survival curves could be observed. Therefore, separate meta-analyses were performed for the first and subsequent years, resulting in a survival rate of the implants of $95.6 \%(95 \% \mathrm{Cl}$ : 93.3\% - 97.9\%) after 12 months, and thereafter an expected decrease of $0.05 \%$ per year $(0.25 \%$ after 5 years). Additionally, a meta-analysis was conducted for the mean MBL after 12 months, resulting in $0.79 \mathrm{~mm}$ of $\mathrm{MBL}(95 \% \mathrm{Cl}: 0.73 \mathrm{~mm}-0.86 \mathrm{~mm})$. Implant bulk material, implant design, restoration type, the application of minor augmentation procedures during surgery as well as the modes of temporization and loading had no statistically significant influence on MBL.

Conclusions: The short-term cumulative survival rates and the MBL of zirconia implants in the presented systematic review are promising. However, additional data are still needed to confirm the long-term predictability of these implants. 


\section{Introduction}

Oral implants represent an important improvement in patients' care since four decades (Brånemark et al. 1977). The gold-standard materials for the fabrication of oral implants are commercially pure titanium or its alloys with expected survival rates of $93-95 \%$ after 10 years when supporting fixed restorations (Jung et al. 2012; Pjetursson et al. 2012). Apart from its well documented benefits, disadvantages of titanium as implant material may be represented by potential discoloration of the periimplant soft tissue (Thoma et al. 2016), possible hypersensitivity (Hosoki et al. 2016) and the debated contribution to peri-implantitis development (Fretwurst et al. 2015). Simultaneously with the introduction of titanium implants, also implants made of alumina $\left(\mathrm{Al}_{2} \mathrm{O}_{3}\right)$ have been commercialized (Sandhaus 1968). Unfortunately, the clinical performance of those ceramic implants was only poorly documented. Alumina implants are nowadays no more available, apparently because of their high risk of fracture (Andreiotelli et al. 2009). Meanwhile, an alternative oxide ceramic material has been introduced. Zirconia (zirconium dioxide, $\mathrm{ZrO}_{2}$ ) presents the phenomenon of allotropy, allowing for a phase transformation toughening mechanism. This results in improved mechanical properties as increased fracture strength and toughness (Garvie et al. 1975). Mostly used as yttria stabilized tetragonal zirconia polycrystal (YTZP), this material has the potential to represent a valid alternative to titanium for the manufacturing of oral implants. Preclinical studies on one-piece zirconia implants addressing their fracture resistance exhibited promising results for their clinical use. Furthermore, in vitro studies proved the biological positive response of osteoblasts and osteoblast-like cells in regard to attachment and proliferation with results similar to titanium (Bächle et al. 2007). Several in vivo studies demonstrated a high biocompatibility of zirconia implants and an excellent degree of osseointegration (Akagawa et al. 1993; Kohal et al. 2004). As for titanium implants, roughened surfaces seem to be beneficial for this purpose (Manzano et al. 2014). The first clinical studies of one-piece zirconia oral implants have been presented in 2006 (Blaschke and Volz 2006; Mellinghoff 2006). However, initial studies were either retrospective or included a limited pool of patients. Since 2010, several prospective clinical trials, evaluating implant survival and $\mathrm{MBL}$, have been performed. The majority of these studies were conducted using one-piece implants while just a few considered newly developed two-piece implants (Becker et al. 2015; Payer et al. 2015). The most recently published systematic review of clinical investigations 
analyzed the survival and success rate of zirconia implants (Hashim et al. 2016). However, a mixture of indications (fixed, removable) and implant designs (e.g. rootanalogue) was included. This resulted in a lack of implications for clinical practice and further research. Furthermore, MBL was not statistically evaluated. Up to the present day, several newly published prospective investigations including up to 5 years of follow-up (Grassi et al. 2015; Jung et al. 2015; Spies et al. 2015a) were not included in any systematic review.

Therefore, the aim of this review was to systematically collect randomized controlled clinical trials and prospective clinical studies available in the literature on zirconia implants restored with fixed prostheses and statistically analyze their behavior in relation to survival rate and MBL. In addition, some other parameters like implant design (one-piece/two-piece), temporization mode (immediate/delayed), loading mode (immediate/delayed), bulk material and the influence of minor augmentation procedures were evaluated. 


\section{Materials and Methods}

This systematic review was conducted following the PRISMA statement (Moher et al. 2009) and the PICO method (Schardt et al. 2007) as applicable in relation to the topic of the review:

- Patient: Partially edentulous patients

- Intervention: Rehabilitation with zirconia implants

- Comparison: Titanium implants

- Outcomes: Survival rate, MBL

\section{Focused Question}

How reliable in terms of implant survival and $\mathrm{MBL}$ are zirconia dental implants restored with SCs and FDPs?

\section{Information Sources and Data Extraction}

The electronic search was performed with the databases MEDLINE (PubMed), Cochrane Library and Embase with a platform-specific search strategy, consisting of combinations of controlled terms (MeSH/EMTREE) and text words. No restrictions regarding the type of study were applied but a language limitation to articles written in English, German, Italian and Spanish language was performed. In addition, a manual search was conducted, screening the references of the included publications for relevant articles. Two reviewers (S.P., B.S.) independently conducted the electronic and manual search and any disagreement was resolved by discussion with a third author (R.K.).

\section{Screening Process}

The search term used for MEDLINE/PubMed was a combination of MeSH and textwords without any filters:

(((((dental implants[MeSH Terms]) AND ceramics[MeSH Terms])) OR ((dental implantation[MeSH Terms]) AND ceramics[MeSH Terms]))) OR (((((zirc*) OR tzp*) OR atz*)) AND ((((implant) OR implants) OR implantation) OR implanted))

The search term for Embase was a combination of EMTREE and text-words limited to humans: 
(((CT=dental implants) $A N D C T=$ ceramics $)) O R(C T=$ dental implantation) $A N D$ $C T=$ ceramics $)))$ OR (((((zirc*) OR tzp*) OR atz*)) AND ((((implant) OR implants) OR implantation) OR implanted)) AND pps= human

Finally, the search performed in the Cochrane Library database can be seen in the appendices (Figure 1).

The search was performed on 2015-11-02 for all mentioned databases. There was no lower limit for the analyzed time frame. Obtained publications were imported into reference management software (EndNote X6, Thomson Reuter, New York, USA) and subsequently screened.

\section{Eligibility Criteria}

In order to achieve a higher level of evidence (at least evidence level III according to the US Agency for Health Care Policy and Research published in 1993) (Appendix Table 1), this review was limited to RCTs and prospective clinical trials that mentioned the survival rate and the MBL of zirconia implants which were restored with SCs or three-unit FDPs. Furthermore, at least fifteen patients per study were required as supplementary inclusion criterion. Two authors (S.P. and B.S.) independently eliminated any duplicate from the gathered results and examined the remaining articles by title and abstract. Subsequently, the full texts were obtained and analyzed for further inclusion/exclusion. In addition, the authors of relevant articles were contacted per email and asked for any further information, if necessary. Both reviewers extracted the data from the included full-text studies and any disagreement was resolved by consensus. Reviewers' agreement was statistically evaluated through the Cohen's kappa $(k)$ test. Further eligible data considered were number of patients/implants at the beginning of the study and at the last follow up, patients mean age, types of restorations (SCs and FDPs), mean observation period [months] of the implants, implant survival rate [\%], MBL [mm], temporization mode (immediate/delayed), loading mode (immediate/delayed), use of augmentation procedures during surgery (yes/no), implant design (one-/two-piece) and implant bulk material (Y-TZP/Alumina Toughened Zirconia; ATZ). 


\section{Risk of Bias}

To reduce the risk of bias, this review was designed according to PRISMAs' checklist and flow diagram. Furthermore, the AMSTAR checklist (A Measurement Tool to Assess Systematic Reviews) was followed, if applicable.

\section{Qualitative Assessment}

The quality assessment was conducted using the Cochrane Collaboration's tool for assessing risk of bias for the evaluation of the RCTs. In addition, the NewcastleOttawa Scale (NOS) was utilized for the analysis of the non-randomized cohorts. Two reviewers (S.P. and B.S.) independently evaluated the included studies. The agreement between the authors was evaluated with the Cohen's kappa (k) test.

\section{Statistical Analyses}

For the MBL after 12 months, a meta-analysis was performed. To take a potential clustering effect within patients into account, computation of study-specific standard errors (SE) was based on the average number of patients and average number of implants. Meta-regression was used to examine the effect of several covariates (as mentioned above) on MBL. For the survival rates, two separate meta-analyses were used, as decreasing survival curves could be observed in the first 12 months and nearly constant curves afterwards. In the first analysis, all reported 1-year survival rates were included. In the second analysis, the available survival rates for those implants were computed, which survived the first year. The study specific SEs of both survival rates were computed combining the averaged observed survival rates and the study specific number of implants/patients. Forest plots were used for graphical presentation. 


\section{Results}

\section{Screening Process}

The initial search yielded 4198 articles. Of those, 1286 were duplicates. After exclusion of the duplicates, as well as of articles irrelevant to the topic of this systematic review, 31 articles remained. Of these 31 articles, a full-text analysis was performed. Thereafter, further 22 articles could not be included in the final analysis. These publications were excluded for one or more of the following reasons: 1) they were designed as retrospective trials, 2) they did not mention the implant MBL or 3) they considered less than fifteen patients (Figure 1).

The screening process resulted in a total of nine articles that could be included into the present systematic review (Table 1). Of these, 2 were randomized controlled clinical trials, whereas 7 were prospective cohort clinical investigations. All included studies were published within the last six years, five of them not until 2015 (Gahlert et al. 2015; Grassi et al. 2015; Jung et al. 2015; Payer et al. 2015; Spies et al. 2015a). All selected articles reported either on single or multiple teeth replacement with implant supported SCs or FDPs. The calculation of the Cohen's kappa coefficient proved an inter-rater agreement of $0.98 \%$. The reasons for exclusion for the 22 articles that were not considered for statistical analyses can be found in Table 2.

\section{Quality Assessment}

RCTs were analyzed with the Cochrane Collaboration's tool for assessing risk of bias (Appendix Table 2). Both RCTs provided sufficient data regarding the sequence generation, allocation concealment and outcome reporting. However, the study of Payer and colleagues (2015) revealed a potential attrition bias. Furthermore, a possible performance bias could be found in both RCTs, mostly owed to impossible blinding of the clinician and the incomplete blinding of the outcome assessor in the study of Cannizzaro et al. (2010). Industrial support represented a questionable font of bias in both cases. The qualitative assessment of the included prospective clinical trials was conducted with the NOS scale for cohort investigations (Appendix Table 3) and resulted in a valuation with 7 stars in most cases. Only 6 stars could be assigned to the investigation of Payer et al. (2013) due to the low follow-up rate $(<80 \%)$ accompanied by an insufficient description of lost patients/implants. Finally, the study of Spies and co-workers (2015a) received an additional star in the category 
comparability for furnishing sufficient data on the peri-implant soft tissue parameters of adjacent teeth. The Cohen's kappa coefficient resulted in $0.91 \%$.

\section{Demographic and Implant Data (Table 1)}

The 9 studies included a total of 326 patients with a mean patient age ranging from 38 to 57.2 years. A total of 398 implants were inserted with a follow-up between 12 (Cannizzaro et al. 2010; Gahlert et al. 2015) and 60 months (Grassi et al. 2015). Studies that included both types of restorations (SCs/FDPs) (Jung et al. 2015; Spies et al. 2015a) or different loading concepts (immediate/delayed) (Cannizzaro et al. 2010), were split and evaluated independently. As a result, 294 implants restored with SCs and 104 implants restored with FDPs were evaluated.

\section{Implant Survival (Figure 2)}

Of the 398 implants placed, 347 were examined to the last follow up. The survival rate after 12 months ranged between 85\% (Cannizzaro et al. 2010) and 100\% (Jung et al. 2015; Spies et al. 2015a). According to the different outcomes of the studies, our meta-analysis resulted in a one-year implant survival rate of $95.6 \%(95 \% \mathrm{Cl}$ : $93.3 \%-97.9 \%$ ). Considering the available data exceeding one year of observation, an expected decrease of $0.05 \%$ per year afterwards was calculated (Figure 3). Most of the implant failures occurred in the early period after placement (Cannizzaro et al. 2010; Grassi et al. 2015; Jung et al. 2015; Kohal et al. 2012; Payer et al. 2013; Spies et al. 2015a).

\section{Marginal Bone Loss (Figure 4)}

The MBL was evaluated at certain follow-ups and measured on standardized radiographs. The MBL values after 12 months ranged between $0.44 \mathrm{~mm}$ (SD: 0.42 $\mathrm{mm}$ ) (Jung et al. 2015) and $1.95 \mathrm{~mm}$ (SD: $1.71 \mathrm{~mm}$ ) (Kohal et al. 2013). The metaanalysis of the 12 months data resulted in a MBL of $0.79 \mathrm{~mm}(95 \% \mathrm{Cl}: 0.73 \mathrm{~mm}$ $0.86 \mathrm{~mm}$ ). Any further meta-analysis of the MBL could not be performed due to the lack of long-term data.

\section{Type of Restorations}

Of the included studies, six solely addressed single tooth replacements (Cannizzaro et al. 2010; Gahlert et al. 2015; Grassi et al. 2015; Kohal et al. 2012; Payer et al. 2013; Payer et al. 2015), whereas only one study solely considered multiple lost teeth, rehabilitated with 3-unit fixed dental prostheses (Kohal et al. 2013). Finally, two 
studies included both indication types (Jung et al. 2015; Spies et al. 2015a) and were, therefore, split in two independent cohorts according to the type of restoration (SC or FDP) and analyzed separately. No statistically significant difference regarding MBL could be observed for SCs $(0.80 \mathrm{~mm})$ and FDPs $(0.76 \mathrm{~mm})$ with the applied meta-analysis $(p=0.455)$.

\section{Implant Temporization}

In seven studies, immediate temporization was performed. Six of these studies described the immediate temporization of the implants with provisional acrylic restorations (Cannizzaro et al. 2010; Grassi et al. 2015; Jung et al. 2015; Kohal et al. 2012; Kohal et al. 2013; Spies et al. 2015a). In the seventh study (Payer et al. 2015), the implants were immediately restored with all-ceramic CAD/CAM provisionals without occlusal contacts and after a healing period of 4 months, the implants were restored with all-ceramic crowns. Finally, in two of the included studies a delayedtemporization concept was preferred. In one study (Gahlert et al. 2015), the provisional restorations were delivered eleven to thirteen weeks after implant placement. In a second investigation (41), abutment connection with a two-piece implant took place 4 to 6 months after implant placement. The meta-analysis did not show a statistically significant difference in MBL (Immediate: $0.79 \mathrm{~mm}$, delayed: 1.05 $\mathrm{mm} ; \mathrm{p} \geq 0.546$ ), when evaluating for an effect of the temporization mode.

\section{Implant Loading}

In one study (Cannizzaro et al. 2010), patients were randomly rehabilitated with either an immediately loaded or a non-immediately loaded prosthesis. The failure rate between the two groups was not statistically significant. An immediate loading concept was also applied in the investigation of Grassi et al. (2015). Five other studies used a non-immediate occlusal loading concept for the rehabilitation of the implants, placing the provisionals out of occlusion. The performed meta-analysis showed no statistically significant influence regarding MBL (Immediate: $0.84 \mathrm{~mm}$, non-immediate: $0.75 \mathrm{~mm} ; \mathrm{p} \geq 0.985$ ), when evaluating for an effect of the loading mode.

\section{Bone Regeneration}

Only two studies did not allow any type of bone augmentation technique during implant placement (Payer et al. 2013; Payer et al. 2015). One investigation included major augmentations at least 3 months before implant placement (Gahlert et al. 
2015). In six studies was stated, that "minor bone augmentation" procedures (Cannizzaro et al. 2010; Gahlert et al. 2015) were applied during surgery. Grassi et al. (2015) described the augmentation procedures as synthetic bone grafts, while other studies (Jung et al. 2015; Kohal et al. 2012; Kohal et al. 2013; Spies et al. 2015a) referred to guided bone regeneration (GBR) procedures with autogenous bone or bovine bone covered with a resorbable membrane. No statistically significant difference regarding MBL $(p \geq 0.815)$ between applied augmentation procedures ( 0.79 $\mathrm{mm})$ and no augmentation procedure during surgery $(0.97 \mathrm{~mm})$ could be calculated.

\section{Implant Design and Implant Bulk Material}

One of the nine included studies evaluated a two-piece implant system (Payer et al. 2015), whereas the others installed a one-piece implant. No statistically significant difference regarding MBL (One-piece: $0.79 \mathrm{~mm}$, two-piece: $1.16 \mathrm{~mm} ; \mathrm{p}=0.586$ ) was observed. In one study (Spies et al. 2015a), the bulk material of the implants consisted of ATZ while the other 8 studies were conducted with implants made from Y-TZP. No statistically significant difference regarding MBL (ATZ: $0.67 \mathrm{~mm}$, Y-TZP: $0.81 \mathrm{~mm} ; \mathrm{p}=0.565$ ) was found. 


\section{Discussion}

\section{Reported Survival Rates}

Relating to the primary outcome, survival rates were used to analyze the clinical performance of the evaluated implants. The parameter survival was mainly defined as an implant remaining in situ irrespective of modifications during the observation period. The statistical analysis of the present review included the nowadays-available data and, furthermore, unpublished survival rates of three ongoing studies, performed by the authors of this review (Jung et al. 2015; Kohal et al. 2012; Kohal et al. 2013). The meta-analysis resulted in a survival rate of $95.6 \%$ after 12 months. This can be considered comparable to titanium implants likewise supporting SCs and FDPs (Jung et al. 2012; Pjetursson et al. 2012). Nevertheless, the cohorts of two included studies showed reduced survival rates of 85 (Cannizzaro et al. 2010) and 88.9\% (Spies et al. 2015a). Cannizzaro et al. (2010) reported in their investigation that all immediately loaded implants installed in extraction sites were lost. Data for immediately restored implants placed in fresh extraction sockets is still rare and a topic of controversial discussion in the literature. Chaushu et al. (2001) could show, that immediately placed and immediately restored two-piece titanium implants resulted in a lower survival rate compared to non-immediate placed and immediately temporized implants. Similarly, Esposito et al. (2015) referred to less complications with delayed implant placement compared to immediate post-extractive implants. Moreover, Cristalli et al. (2015) advised, that selection of patients and a rigorous clinical protocol are fundamental for post extraction implant placement and loading. Therefore, immediate restoration of immediately placed implants might result in reduced survival rates, irrespective of the implant material. A second cohort with reduced survival rate was found in the study of Spies et al. (2015a), where a new tapered implant design was investigated. The authors reported that the first three implants placed did not osseointegrate, whereas all subsequently installed implants remained in situ at the three-year follow-up. They concluded that a certain learning curve might be necessary in order how to handle one-piece implants. Finally, the short-term survival rates from the included studies showed positive results and might, therefore, be considered promising. 


\section{Applied Success Criteria/MBL}

Due to the heterogeneity of the applied success criteria in the included studies (Albrektsson et al. 1986; Buser et al. 1990; Naert et al. 1992; Östman et al. 2007), any comparisons of the reported success rates would not be appropriate. As clearly shown in the investigations of Kohal et al. (2012; 2013), the evaluation of marginal bone level changes might be the most important criterion for the assessment of success of dental implants. In their investigations, survival rates as high as 95.4 and $98.2 \%$ could be observed after one year. However, when considering MBL as success criterion, only 66 and $62 \%$ of the implants could be assigned to success grade I ( $\leq 2 \mathrm{~mm}$ of MBL) and 86 and $87 \%$ of the implants to success grade II ( $\leq 3 \mathrm{~mm}$ of MBL) (Östman et al. 2007). Therefore, the evaluation of marginal bone-level changes was considered mandatory for inclusion in the present review. According to the conclusions stated at the consensus report of the Proceedings of the $1^{\text {st }}$ European Workshop on Periodontology, a MBL $<1.5 \mathrm{~mm}$ after one year of functional loading and of $0.2 \mathrm{~mm}$ annually thereafter might be defined a successful treatment outcome. The meta-analysis conducted in our systematic review resulted in a MBL of $0.79 \mathrm{~mm}$ after 12 months what might be considered a successful outcome after one year. Furthermore, no covariates were found to significantly affect MBL. Thus, the MBL of zirconia implants can be considered similar to the ones reported for titanium implants. Even though, due to the heterogeneity of the included studies and some controversial results, more data is necessary for final evaluation of this topic.

\section{Suitability of the Search Strategy}

Limiting the database search to combinations of MeSH terms is a common procedure (Jung et al. 2012; Pjetursson et al. 2012). For the electronic search strategy of the present review, a combination of MeSH terms and text words was utilized to enhance the sensibility of the search and minimize the risk of inadvertent exclusion of relevant articles. Processing of newly published articles in MEDLINE takes a considerable amount of time. Therefore, a strategy limited to MeSH terms might result in a loss of relevant data. For example, no MeSH terms had been assigned to 4 included studies in November 2015. Consequently, the authors recommend combining different specific MeSH terms with various combinations of adequate text words. 


\section{Implant Bulk Materials and Surface Treatments}

Regarding the implant bulk material, the majority of the included studies involved implants produced from Y-TZP, whereas only one study investigated newly developed ATZ implants coated with Y-TZP (Spies et al. 2015a). However, implants exclusively produced from ATZ are market-available. ATZ is an oxide ceramic composite material with increased fracture strength and reduced aging susceptibility (Kohorst et al. 2012; Spies et al. 2015b; Spies et al. 2016a). To date, no clinical studies including implants exclusively made of ATZ can be found in the literature. However, there is some evidence from preclinical animal studies (Kohal et al. 2016; Schierano et al. 2015), suggesting an osseointegration capability comparable to YTZP.

\section{Soft Tissue Parameters}

Because of the lack (Cannizzaro et al. 2010) and the heterogeneity of the presented data, no statistical evaluation of the soft tissue parameters could be performed. Predominantly, soft tissue measurements were performed at each follow-up and described as secondary outcomes after survival rate and MBL. Various parameters were screened, although mostly using different measurements methods (e.g. bleeding on probing, probing depth, clinical attachment loss, bleeding indices, plaque indices, gingival recessions and papilla height). In addition to the peri implant evaluations, the adjacent teeth were frequently taken as references. In one investigation, solely a "healthy soft tissue" (Jung et al. 2015) in the peri-implant area was described, whereas others found decreased bleeding and plaque indices in the course of the follow-ups (Kohal et al. 2012; Kohal et al. 2013; Payer et al. 2013). However, significantly different results in relation to reference teeth were described for probing depth and other parameters (Kohal et al. 2012; Kohal et al. 2013). Moreover, comparison of parameters across studies revealed heterogeneous outcomes. For statistical analyses, standardized and identical soft-tissue evaluations would have been necessary.

\section{Limits and Risk of Bias of the Review}

It has to be mentioned that the principal limits of the present review can be found in the lack of high quality controlled clinical trials and the short-term follow up of most of the included studies. In regard to the main risk of bias of the included studies, an industrial involvement was found for all mentioned investigations. Apart from the 
above-mentioned limits, the authors prepared this review in respect of the nowadays available and recommended guidelines.

\section{Implications for clinical practice and further research}

For restoring single tooth gaps and replacing up to three adjacent missing teeth, zirconia implants can be considered a treatment option with an outcome comparable to titanium implants. There are no sufficient data available addressing extended indications. Based on the performed analyses, the timepoint of temporization and loading has no influence on $\mathrm{MBL}$, indicating that there is no need for protective splints during the healing period. Although one-piece implants do not allow for primary wound closer, minor augmentation procedures during implant installation showed no significant effect on MBL. However, especially for unexperienced surgeons and prosthodontists, correct placement of one-piece implants and immediate temporization might be a challenging demand. Furthermore, patient selection is considered a crucial point for this indication. This might explain the calculated failure rate of $4.4 \%$ within the early healing period and suggests a learning curve even for experienced dentists like described by Spies et al. (2015a). However, implants surviving the first year can be considered at low risk of failure $(0.05 \%$ per year). To overcome the limitations of one-piece implants, further research should address the long-term stability of two-piece zirconia implants, before evaluating their reliability clinically. 


\section{Conclusion}

An increasing interest for zirconia and its composites as dental implant materials has been shown in the very last years, testified by numerous clinical studies published on this topic. Based on the present systematic review, the survival rate and marginal bone loss of zirconia dental implants supporting SCs and FDPs after one year are promising and, furthermore, comparable to available data of two-piece titanium implants. However, more high evidence level clinical studies are needed to confirm the long-term predictability of these implants.

\section{Acknowledgements}

The present review was not supported by any funding. The authors declare no potential conflicts of interest with respect to the authorship and/or publication of this article.

\section{Author Contribution}

S. Pieralli contributed to the design of the review, data acquisition, data interpretation and analysis and wrote the manuscript.

R. J. Kohal contributed to the design of the review, data acquisition and interpretation and critically revised the manuscript.

R. E. Jung contributed to data analysis and critically revised the manuscript.

K. Vach performed the statistical analysis and critically revised the manuscript.

B. C. Spies contributed to the design of the review, data acquisition, data interpretation and critically revised the manuscript.

All authors gave final approval and agree to be accountable to all aspects of the work. 


\section{Summary}

Dental implants made of zirconia are commercially available since several years. Besides numerous promising pre-clinical investigations, an increasing number of clinical investigations were published in the last years, especially in 2015. Therefore, the aim of this review was to systematically analyze the behavior of zirconia oral implants restored with fixed restorations, in relation to survival rate and marginal bone. Furthermore, the eventual influence of many different covariates was also evaluated. The design of this review followed the PRISMA guidelines, the AMSTAR checklist and the PICO method. A comprehensive search through the main databases (MEDLINE/PubMed, Cochrane Library and Embase) and text references was performed up to November 2015. The inclusion criteria were defined as follows: (1) Fixed restoration (single crowns or three-unit fixed dental prostheses), (2) calculation of survival rate, (3) calculation of mean marginal bone loss, (4) prospective study design and (5) minimum of fifteen included patients. From the initial screening a total of 4198 articles were obtained, furthermore, the full-text of 31 articles was extracted. Thereafter, additional 22 full-text articles were excluded and 9 studies were finally included (5 of them published in 2015) in this review. Additionally, unpublished data (three years of follow up) of three included studies were obtained. For the meta-analysis, the datasets were split in relation to the type of restoration and independently analyzed. Two separate meta-analyses were conducted in relation to the survival rate, after 12 months and the further follow-ups. In addition, a metaanalysis was performed to evaluate the mean marginal bone loss (MBL) after 12 months and the eventual influence on it of several covariates. To assess the quality of the included studies the most recommended rating scales were used: the Cochrane Collaboration's tool for assessing risk of bias for the RCTs and the Newcastle-Ottawa Scale (NOS) for the non-randomized investigations. According to our meta-analysis, the survival rate after one year was of $95.6 \%(95 \% \mathrm{Cl}$ : $93.3 \%$ $97.9 \%)$ with a further decrease of $0.05 \%$ per year afterwards $(0.25 \%$ after 5 years). Furthermore, the statistical evaluation of the peri-implant marginal bone loss resulted in $0.79 \mathrm{~mm}(95 \% \mathrm{Cl}: 0.73 \mathrm{~mm}-0.86 \mathrm{~mm})$ with no statistically significant influence of any of the evaluated parameters. From the authors' point of view, a 12-monthsurvival in the range of $95 \%$ without significant decrease afterwards and the calculated amount of marginal bone loss $<1 \mathrm{~mm}$ can be considered highly successful. 


\section{Figure Legends}

Figure 1: $\quad$ Flow chart of studies selection according to the PRISMA guidelines

Figure 2: $\quad$ Forest plot of the survival rate after 12 months

Figure 3: $\quad$ Ongoing survival of implants surviving the first 12 months

Figure 4: $\quad$ Forest plot of MBL after 12 months 


\section{Tables}

Table 1: Results of the included and analyzed articles ( $Y=Y-T Z P, A=A T Z)$

\begin{tabular}{|c|c|c|c|c|c|c|c|c|c|c|c|}
\hline & $\begin{array}{l}\stackrel{0}{ \pm} \\
\stackrel{0}{0} \\
\stackrel{ \pm}{\pi} \\
0\end{array}$ & 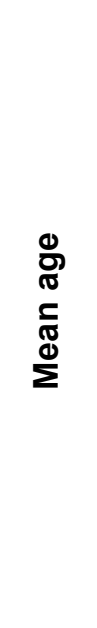 & $\begin{array}{l}\stackrel{n}{\frac{D}{5}} \\
\frac{\bar{\sigma}}{0} \\
\underline{\underline{E}}\end{array}$ & 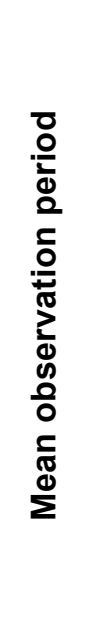 & 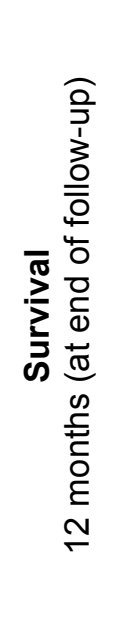 & 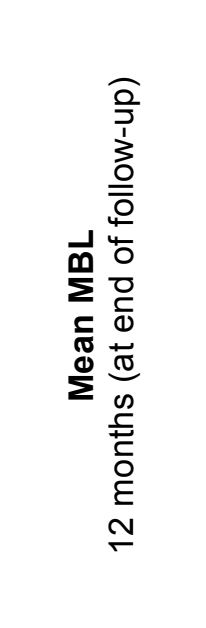 & 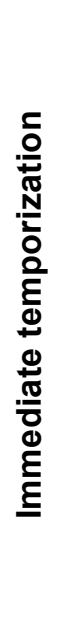 & 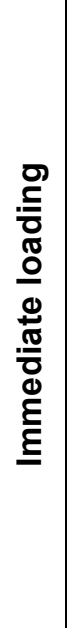 & 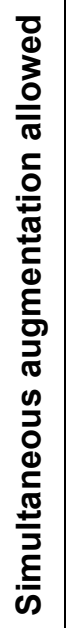 & 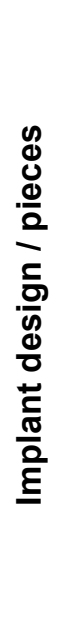 & 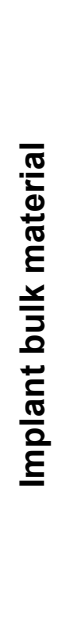 \\
\hline & $n$ & {$[y]$} & $n$ & {$[m]$} & {$[\%]$} & {$[\mathrm{mm}]$} & & & & & \\
\hline $\begin{array}{l}\text { Cannizzaro et al. (2010) } \\
\text { [no immediate loading] }\end{array}$ & 20 & 39 & 20 & 12 & $\begin{array}{l}90 \\
(-)\end{array}$ & $\begin{array}{c}0.72 \pm 0.59 \\
(-)\end{array}$ & $x$ & & $x$ & 1 & $\mathrm{Y}$ \\
\hline $\begin{array}{l}\text { Cannizzaro et al. (2010) } \\
\text { [immediate loading] }\end{array}$ & 20 & 38 & 20 & 12 & $\begin{array}{c}85.0 \\
(-)\end{array}$ & $\begin{array}{c}0.9 \pm 0.48 \\
(-)\end{array}$ & $x$ & $x$ & $x$ & 1 & $\mathrm{Y}$ \\
\hline Payer et al. (2013) & 20 & 44.4 & 20 & 17.1 & $\begin{array}{c}95 \\
(95)\end{array}$ & $\begin{array}{c}0.81 \pm 1 \\
(1.29 \pm 0.1)\end{array}$ & $x$ & & & 1 & $\mathrm{Y}$ \\
\hline Payer et al. (2015) & 12 & 46 & 16 & 19.7 & $\begin{array}{c}93.3 \\
(93.3)\end{array}$ & $\begin{array}{c}1.16 \pm 1.01 \\
(1.48 \pm 1.05)\end{array}$ & & & & 2 & $Y$ \\
\hline Kohal et al. (2012) & 65 & 39.3 & 66 & 36.9 & $\begin{array}{l}95.5 \\
(90.8)\end{array}$ & $\begin{array}{c}1.31 \pm 1.49 \\
(-)\end{array}$ & $x$ & & $x$ & 1 & $\mathrm{Y}$ \\
\hline Kohal et al. (2013) & 28 & 53.6 & 56 & 36.9 & $\begin{array}{c}98.2 \\
(98.2)\end{array}$ & $\begin{array}{c}1.95 \pm 1.71 \\
(-)\end{array}$ & $x$ & & $x$ & 1 & $\mathrm{Y}$ \\
\hline Gahlert et al. (2015) & 44 & 48 & 44 & 12.5 & $\begin{array}{c}97.6 \\
(-)\end{array}$ & $\begin{array}{c}1.02 \pm 0.9 \\
(-)\end{array}$ & & & $x$ & 1 & $\mathrm{Y}$ \\
\hline $\begin{array}{l}\text { Spies et al. (2015a) } \\
\text { [single crowns] }\end{array}$ & 27 & 44.4 & 27 & 36.8 & $\begin{array}{c}88.9 \\
(88.5)\end{array}$ & $\begin{array}{c}0.46 \pm 0.54 \\
(0.47 \pm 0.49)\end{array}$ & $x$ & & $x$ & 1 & A \\
\hline $\begin{array}{l}\text { Spies et al. (2015a) } \\
\text { [fixed dental prostheses] }\end{array}$ & 13 & 57.2 & 26 & 37.1 & $\begin{array}{c}100 \\
(100)\end{array}$ & $\begin{array}{c}1.08 \pm 0.67 \\
(1.07 \pm 0.68)\end{array}$ & $x$ & & $X$ & 1 & A \\
\hline $\begin{array}{l}\text { Jung et al. (2015) } \\
\text { [single crowns] }\end{array}$ & 49 & 47.1 & 49 & 34.8 & $\begin{array}{c}97.9 \\
(97.7)\end{array}$ & $\begin{array}{c}0.66 \pm 0.61 \\
(-)\end{array}$ & $x$ & & $x$ & 1 & $\mathrm{Y}$ \\
\hline $\begin{array}{l}\text { Jung et al. (2015) } \\
\text { [fixed dental prostheses] }\end{array}$ & 11 & 54.1 & 22 & 36.5 & $\begin{array}{c}100 \\
(100)\end{array}$ & $\begin{array}{c}0.44 \pm 0.42 \\
(-)\end{array}$ & $x$ & & $x$ & 1 & $\mathrm{Y}$ \\
\hline Grassi et al. (2015) & 17 & 52.3 & 32 & 61.2 & $\begin{array}{c}96.9 \\
(96.8)\end{array}$ & $\begin{array}{c}0.83 \pm 0.24 \\
(1.23 \pm 0.29)\end{array}$ & $x$ & $x$ & $x$ & 1 & $\mathrm{Y}$ \\
\hline
\end{tabular}


Table 2: Reasons for exclusion when screening the 31 full-text articles

\begin{tabular}{|l|l|}
\hline \multicolumn{1}{|c|}{ Authors } & \multicolumn{1}{c|}{ Reason(s) for Exclusion } \\
\hline Bankoğlu Gungor et al. (2014) & No patients \\
\hline Becker et al. (2015) & No MBL measurements \\
\hline Blaschke and Volz (2006) & No MBL measurements, retrospective design \\
\hline Borgonovo et al. (2010) & No value for mean MBL provided \\
\hline Borgonovo et al. (2011) & $<15$ patients \\
\hline Borgonovo et al. (2012) & $<15$ patients \\
\hline Borgonovo et al. (2013a) & $<15$ patients \\
\hline Borgonovo et al. (2013b) & $<15$ patients \\
\hline Borgonovo et al. (2013c) & $<15$ patients, No MBL measurements \\
\hline Borgonovo et al. (2015) & Retrospective design \\
\hline Brüll et al. (2014) & No value for mean MBL provided \\
\hline Cionca et al. (2015) & Retrospective design \\
\hline Gahlert et al. (2013) & No zirconia implants \\
\hline Kollar et al. (2008) & No MBL measurements, retrospective design \\
\hline Lambrich and lglhaut (2008) & No MBL measurements, retrospective design \\
\hline Mellinghoff (2006) & No MBL measurements, retrospective design \\
\hline Oliva et al. (2007) & No MBL measurements \\
\hline Oliva et al. (2010) & Case report \\
\hline Pirker and Kocher (2008) & $<15$ patients, No MBL measurements \\
\hline Pirker and Kocher (2009) & Retrospective design \\
\hline Roehling et al. (2015) & Same cohort in Spies et al. (2015a) \\
\hline Spies et al. (2016b) &
\end{tabular}




\section{References}

Akagawa Y, Ichikawa Y, Nikai H, Tsuru H. 1993. Interface histology of unloaded and early loaded partially stabilized zirconia endosseous implant in initial bone healing. J Prosthet Dent. 69 (6):599-604.

Albrektsson T, Zarb G, Worthington P, Eriksson AR. 1986. The long-term efficacy of currently used dental implants: a review and proposed criteria of success. Int J Oral Maxillofac Implants. 1 (1):11-25.

Andreiotelli M, Wenz HJ, Kohal RJ. 2009. Are ceramic implants a viable alternative to titanium implants? A systematic literature review. Clin Oral Implants Res. 20 (4 Suppl):32-47.

Bächle M, Butz F, Hubner U, Bakalinis E, Kohal RJ. 2007. Behavior of CAL72 osteoblast-like cells cultured on zirconia ceramics with different surface topographies. Clin Oral Implants Res. 18 (1):53-59.

Bankoğlu Gungor M, Aydin C, Yilmaz H, Gül EB. 2014. An overview of zirconia dental implants: basic properties and clinical application of three cases. J Oral Implantol. 40 (4):485-494.

Becker J, John G, Becker K, Mainusch S, Diedrichs G, Schwarz F. 2015. Clinical performance of two-piece zirconia implants in the posterior mandible and maxilla: a prospective cohort study over 2 years. Clin Oral Implants Res. [accessed 2015 May 6]; http://dx.doi.org/10.1111/clr.12610. doi:10.1111/clr.12610 [ePub].

Blaschke C, Volz U. 2006. Soft and hard tissue response to zirconium dioxide dental implants - a clinical study in man. Neuro Endocrinol Lett. 27 (4 Suppl):69-72.

Borgonovo A, Censi R, Dolci M, Vavassori V, Bianchi A, Maiorana C. 2011. Use of endosseous one-piece yttrium-stabilized zirconia dental implants in premolar region: a two-year clinical preliminary report. Minerva Stomatol. 60 (5):229-241. 
Borgonovo AE, Arnaboldi O, Censi R, Dolci M, Santoro G. 2010. Edentulous jaws rehabilitation with yttrium-stabilized zirconium dioxide implants: two years follow-up experience. Minerva Stomatol. 59 (7-8):381-392.

Borgonovo AE, Fabbri A, Vavassori V, Censi R, Maiorana C. 2012. Multiple teeth replacement with endosseous one-piece yttrium-stabilized zirconia dental implants. Med Oral Patol Oral Cir Bucal. 17 (6):981-987.

Borgonovo AE, Censi R, Vavassori V, Dolci M, Calvo-Guirado JL, Delgado Ruiz RA, Maiorana C. 2013a. Evaluation of the success criteria for zirconia dental implants: a four-year clinical and radiological study. Int J Dent. [accessed 2013 Aug 26]; http://dx.doi.org/10.1155/2013/463073. doi:10.1155/2013/463073 [ePub].

Borgonovo AE, Corrocher G, Dolci M, Censi R, Vavassori V, Maiorana C. 2013b. Clinical evaluation of zirconium dental implants placed in esthetic areas: a case series study. Eur J Esthet Dent. 8 (4):532-545.

Borgonovo AE, Vavassori V, Censi R, Calvo JL, Re D. 2013c. Behavior of endosseous one-piece yttrium stabilized zirconia dental implants placed in posterior areas. Minerva Stomatol. 62 (7-8):247-257.

Borgonovo AE, Censi R, Vavassori V, Arnaboldi O, Maiorana C, Re D. 2015. Zirconia implants in esthetic areas: 4-year follow-up evaluation study. Int J Dent. [accessed 2015 Jun 1]; http://dx.doi.org/10.1155/2015/415029. doi:10.1155/2015/415029 [ePub].

Brånemark PI, Hansson BO, Adell R, Breine U, Lindström J, Hallèn O, Ohman A. 1977. Osseointegrated implants in the treatment of the edentulous jaw. Experience from a 10-year period. Scand J Plast Reconstr Surg Suppl. 16:1-132.

Brüll F, van Winkelhoff AJ, Cune MS. 2014. Zirconia dental implants: a clinical, radiographic, and microbiologic evaluation up to 3 years. Int J Oral Maxillofac Implants. 29 (4):914-920. 
Buser D, Weber HP, Lang NP. 1990. Tissue integration of non-submerged implants. 1-year results of a prospective study with 100 ITI hollow-cylinder and hollow-screw implants. Clin Oral Implants Res. 1 (1):33-40.

Cannizzaro G, Torchio C, Felice P, Leone M, Esposito M. 2010. Immediate occlusal versus non-occlusal loading of single zirconia implants. A multicentre pragmatic randomised clinical trial. Eur J Oral Implantol. 3 (2):111-120.

Chaushu G, Chaushu S, Tzohar A, Dayan D. 2001. Immediate loading of single-tooth implants: immediate versus non-immediate implantation. A clinical report. Int J Oral Maxillofac Implants. 16 (2):267-272.

Cionca N, Müller N, Mombelli A. 2015. Two-piece zirconia implants supporting allceramic crowns: a prospective clinical study. Clin Oral Implants Res. 26 (4):413-418.

Cristalli MP, Marini R, La Monaca G, Sepe C, Tonoli F, Annibali S. 2015. Immediate loading of post-extractive single-tooth implants: a 1-year prospective study. Clin Oral Implants Res. 26 (9):1070-1079.

Esposito M, Barausse C, Pistilli R, Jacotti M, Grandi G, Tuco L, Felice P. 2015. Immediate loading of post-extractive versus delayed placed single implants in the anterior maxilla: outcome of a pragmatic multicenter randomised controlled trial 1year after loading. Eur J Oral Implantol. 8 (4):347-358.

Fretwurst T, Buzanich G, Nahles S, Woelber JP, Riesemeier H, Nelson K. 2015. Metal elements in tissue with dental peri-implantitis: a pilot study. Clin Oral Implants Res. [accessed 2015 Oct 27]; http://dx.doi.org/10.1111/clr.12718. doi:10.1111/clr.12718 [ePub].

Gahlert M, Burtscher D, Pfundstein G, Grunert I, Kniha H, Roehling S. 2013. Dental zirconia implants up to three years in function: a retrospective clinical study and evaluation of prosthetic restorations and failures. Int J Oral Maxillofac Implants. 28 (3):896-904. 
Gahlert M, Kniha H, Weingart D, Schild S, Gellrich NC, Bormann KH. 2015. A prospective clinical study to evaluate the performance of zirconium dioxide dental implants in single-tooth gaps. Clin Oral Implants Res. [accessed 2016 Apr 1]; http://dx.doi.org/10.1111/clr.12598. doi:10.1111/clr.12598 [ePub].

Garvie RC, Hannink RH, Pascoe RT. 1975. Ceramic steel? Nature. 258 (5537):703704.

Grassi FR, Capogreco M, Consonni D, Bilardi G, Buti J, Kalemaj Z. 2015. Immediate occlusal loading of one-piece zirconia implants: five-year radiographic and clinical evaluation. Int J Oral Maxillofac Implants. 30 (3):671-680.

Hashim D, Cionca N, Courvoisier DS, Mombelli A. 2016. A systematic review of the clinical survival of zirconia implants. Clin Oral Investig. [accessed 2016 May 24]; http://dx.doi.org/10.1007/s00784-016-1853-9. doi:10.1007/s00784-016-1853-9 [ePub].

Hosoki M, Nishigawa K, Miyamoto Y, Ohe G, Matsuka Y. 2016. Allergic contact dermatitis caused by titanium screws and dental implants. J Prosthodont Res. [accessed: 2016 Jan 8]; http://linkinghub.elsevier.com/retrieve/pii/S18831958(15)00111-5. doi:10.1016/j.jpor.2015.12.004 [ePub].

Jung RE, Zembic A, Pjetursson BE, Zwahlen M, Thoma DS. 2012. Systematic review of the survival rate and the incidence of biological, technical, and aesthetic complications of single crowns on implants reported in longitudinal studies with a mean follow-up of 5 years. Clin Oral Implants Res. 23 (4 Suppl):2-21.

Jung RE, Grohmann P, Sailer I, Steinhart YN, Feher A, Hämmerle C, Strub JR, Kohal R. 2015. Evaluation of a one-piece ceramic implant used for single-tooth replacement and three-unit fixed partial dentures: a prospective cohort clinical trial. Clin Oral Implants Res. [accessed 2015 Jul 27]; http://dx.doi.org/10.1111/clr.12670. doi:10.1111/clr.12670 [ePub]. 
Kohal RJ, Weng D, Bächle M, Strub JR. 2004. Loaded custom-made zirconia and titanium implants show similar osseointegration: an animal experiment. J Periodontol. 75 (9):1262-1268.

Kohal RJ, Knauf M, Larsson B, Sahlin H, Butz F. 2012. One-piece zirconia oral implants: one-year results from a prospective cohort study. 1. Single tooth replacement. J Clin Periodontol. 39 (6):590-597.

Kohal RJ, Patzelt SB, Butz F, Sahlin H. 2013. One-piece zirconia oral implants: oneyear results from a prospective case series. 2 . Three-unit fixed dental prosthesis (FDP) reconstruction. J Clin Periodontol. 40 (5):553-562.

Kohal RJ, Bächle M, Renz A, Butz F. 2016. Evaluation of alumina toughened zirconia implants with a sintered, moderately rough surface: An experiment in the rat. Dent Mater. 32 (1):65-72.

Kohorst P, Borchers L, Strempel J, Stiesch M, Hassel T, Bach FW, Hubsch C. 2012. Low-temperature degradation of different zirconia ceramics for dental applications. Acta Biomater. 8 (3):1213-1220.

Kollar A, Huber S, Mericske E, Mericske-Stern R. 2008. Zirconia for teeth and implants: a case series. Int J Periodontics Restorative Dent. 28 (5):479-487.

Lambrich M, Iglhaut G. 2008. Vergleich der Überlebensrate von Zirkondioxid- und Titanimplantaten. Z Zahnärztl Impl. 24 (3):182-191.

Manzano G, Herrero LR, Montero J. 2014. Comparison of clinical performance of zirconia implants and titanium implants in animal models: a systematic review. Int J Oral Maxillofac Implants. 29 (2):311-320.

Mellinghoff J. 2006. Erste klinische Ergebnisse zu dentalen Schraubenimplantaten aus Zirkonoxid. Z Zahnärztl Impl. 22:288-293. 
Moher D, Liberati A, Tetzlaff J, Altman DG, Group P. 2009. Preferred reporting items for systematic reviews and meta-analyses: the PRISMA Statement. Open Med. 3 (3):123-130.

Naert I, Quirynen M, van Steenberghe D, Darius P. 1992. A six-year prosthodontic study of 509 consecutively inserted implants for the treatment of partial edentulism. J Prosthet Dent. 67 (2):236-245.

Oliva J, Oliva X, Oliva JD. 2007. One-year follow-up of first consecutive 100 zirconia dental implants in humans: a comparison of 2 different rough surfaces. Int $\mathrm{J}$ Oral Maxillofac Implants. 22 (3):430-435.

Oliva J, Oliva X, Oliva JD. 2010. Five-year success rate of 831 consecutively placed Zirconia dental implants in humans: a comparison of three different rough surfaces. Int J Oral Maxillofac Implants. 25 (2):336-344.

Östman PO, Hellman M, Albrektsson T, Sennerby L. 2007. Direct loading of Nobel Direct and Nobel Perfect one-piece implants: a 1-year prospective clinical and radiographic study. Clin Oral Implants Res. 18 (4):409-418.

Payer M, ArnetzI V, Kirmeier R, Koller M, Arnetzl G, Jakse N. 2013. Immediate provisional restoration of single-piece zirconia implants: a prospective case series results after 24 months of clinical function. Clin Oral Implants Res. 24 (5):569-575.

Payer M, Heschl A, Koller M, Arnetzl G, Lorenzoni M, Jakse N. 2015. All-ceramic restoration of zirconia two-piece implants - a randomized controlled clinical trial. Clin Oral Implants Res. 26 (4):371-376.

Pirker W, Kocher A. 2008. Immediate, non-submerged, root-analogue zirconia implant in single tooth replacement. Int J Oral Maxillofac Surg. 37 (3):293-295.

Pirker W, Kocher A. 2009. Immediate, non-submerged, root-analogue zirconia implants placed into single-rooted extraction sockets: 2-year follow-up of a clinical study. Int J Oral Maxillofac Surg. 38 (11):1127-1132. 
Pjetursson BE, Thoma D, Jung R, Zwahlen M, Zembic A. 2012. A systematic review of the survival and complication rates of implant-supported fixed dental prostheses (FDPs) after a mean observation period of at least 5 years. Clin Oral Implants Res. 23 (6 Suppl):22-38.

Roehling S, Woelfler H, Hicklin S, Kniha H, Gahlert M. 2015. A retrospective clinical study with regard to survival and success rates of zirconia implants up to and after 7 years of loading. Clin Implant Dent Relat Res. 18 (3):545-558.

Sandhaus S. 1968. Tecnica e strumentario dell'impianto C.B.S. (Cristalline Bone Screw). Inf Odontostomatol. 4 (3):19-24.

Schardt C, Adams MB, Owens T, Keitz S, Fontelo P. 2007. Utilization of the PICO framework to improve searching PubMed for clinical questions. BMC Med Inform Decis Mak. 7:16.

Schierano G, Mussano F, Faga MG, Menicucci G, Manzella C, Sabione C, Genova T, von Degerfeld MM, Peirone B, Cassenti A et al. 2015. An alumina toughened zirconia composite for dental implant application: in vivo animal results. Biomed Res Int. [accessed 2015 Apr 6]; http://dx.doi.org/10.1155/2015/157360. doi:10.1155/2015/157360 [ePub].

Spies BC, Balmer M, Patzelt SB, Vach K, Kohal RJ. 2015a. Clinical and patientreported outcomes of a zirconia oral implant: Three-year results of a prospective cohort investigation. J Dent Res. 94 (10):1385-1391.

Spies BC, Sauter C, Wolkewitz M, Kohal RJ. 2015b. Alumina reinforced zirconia implants: effects of cyclic loading and abutment modification on fracture resistance. Dent Mater. 31 (3):262-272.

Spies BC, Nold J, Vach K, Kohal RJ. 2016a. Two-piece zirconia oral implants withstand masticatory loads: An investigation in the artificial mouth. J Mech Behav Biomed Mater. 53:1-10. 
Spies BC, Sperlich M, Fleiner J, Stampf S, Kohal RJ. 2016b. Alumina reinforced zirconia implants: 1-year results from a prospective cohort investigation. Clin Oral Implants Res. 27 (4):481-490.

Thoma DS, loannidis A, Cathomen E, Hämmerle CH, Hüsler J, Jung RE. 2016.

Discoloration of the peri-implant mucosa caused by zirconia and titanium implants. Int J Periodontics Restorative Dent. 36 (1):39-45. 